\title{
A Historical Review of Ameloblastoma
}

\author{
Sneha Elza ${ }^{1}$, Dr J. Jananee ${ }^{2}$, Dr. Lakshmi Ravi ${ }^{3}$ \\ ${ }^{1}$ Student, Asan Memorial Dental College and Hospital, Chengalpattu \\ ${ }^{2}$ Reader, Department of Oral Pathology, Asan Memorial Dental College and Hospital, Chengalpattu \\ ${ }^{3}$ Professor \& HOD, Department of Orthodontics, Asan Memorial Dental College and Hospital, Chengalpattu
}

\begin{abstract}
Ameloblastoma is a true neoplasm of the enamel organ type tissue which does not undergo differentiation to the point of enamel formation. The term unicystic is derived from the macroscopic and microscopic appearance of the lesion.
\end{abstract}

Keywords: Plexiform, Follicular, granulomatous

\section{Introduction}

Ameloblastoma is a true neoplasm of the enamel organ type tissue which does not undergo differentiation to the point of enamel formation. The term unicystic is derived from the macroscopic and microscopic appearance of the lesion. It is a well-defined, often large monocytic cavity with a lining focally, but rarely entirely composed of odontogenic (ameloblastomatous) epithelium. Predominant radiographical patterns for Unicystic Ameloblastoma are unilocular, scalloped, macromultilocular, pericoronal, interradicular, or periapical expansile radiolucencies.

Many benign lesions cause mandibular swellings, whose origin can be, attributed to odontogenic or non-odontogenic causes. The most commonly encountered are ameloblastomas, radicular cysts, DCs, OKCs, central giant cell granulomas, fibro-osseous lesions and osteomas.[4] The most common tumor of odontogenic origin is ameloblastoma, which develops from epithelial cellular elements and dental tissues in their various phases of development.[2] The unicystic type of ameloblastoma is one of the least encountered variant of the ameloblastoma accounting for about $10-15 \%$ of all ameloblatomas.[느므]

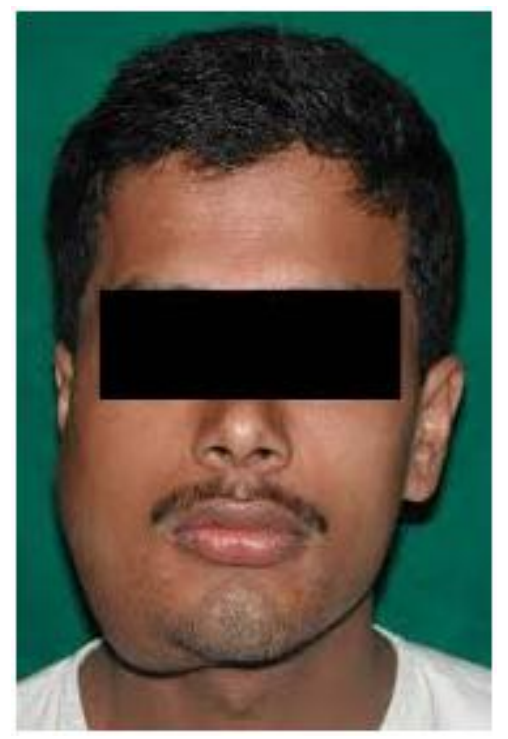

Historical Review Cusack JW (1827) first published a case, which was obviously an ameloblastoma. But, the detailed histopathological description was first made by Wedl (1853). He called the tumour, "Cystosarcoma or Cystosarcoma Adenoids", but suggested that it could have arisen from a tooth bud or from the dental lamina. Broca (1868) gave the first detailed description of solid/multicystic ameloblastoma, whereas the first histological drawing of ameloblastoma was made by Wagstaffe (1871). The detailed description of ameloblastoma was made by Falksson (1879). Malassez (1885) suggested the name "Epithelioma Adamantin". Derjinsky (1890) suggested the term "Adamantinoma". Ivey and Churchill (1930) used the name "Ameloblastoma". The first case of Peripheral Ameloblastoma, was made by Stanley and Krough (1959) [3],[7]. The concept of Unicystic Ameloblastoma (UA) was first introduced by Robinson and Martinez (1977), where they associated UA with dentigerous cysts, cytogenic ameloblastoma, extensive dentigerous cysts with intracystic ameloblastic papilloma, mural ameloblastoma, dentigerous cysts with ameloblastomatous proliferation and ameloblastoma developing in a radicular (or “globulomaxillary") cyst [8],[9].Gardner DG (1981) described a subtype of UA, plexiform UA, where the inner surface of the cyst may show one or several polypoid or papillomatous, pedunculated, exophytic masses, which in rare cases, fill the entire cyst lumen [10]. This subtype has also been called as intracystic, luminal or intraluminal ameloblastoma [9]. Ameloblastoma is a true neoplasm of the enamel organ type tissue which does not undergo differentiation to the point of enamel formation. Robinson (1937) described it as unicentric, nonfunctional, intermittent in growth, anatomically benign and clinically persistent [3],[4]. WHO (1992) has described Ameloblastoma as a benign, locally aggressive, polymorphic neoplasm, which is presumably derived from the intraosseous remnants of the odontogenic epithelium.[5],[6] Various synonyms which are used for ameloblastoma are Adamantinoma, Adamantoblastoma, Epithelioma Adamantin, Multilocular Cyst, Adontomes embryolastiques and Epithelial odontoma [3],[7]. A recently published biological profile based on 3,677 ameloblastoma cases, has clearly demonstrated that it is no longer appropriate in any scientific study to use the diagnosis of ameloblastoma without specifying the type. Hence, based on clinical and radiographical characteristics, histopathology, and behavioural and prognostic features, subtypes or variants of ameloblastomas can be presently distinguished as follows [7]: 1. The classic solid / 


\section{International Journal of Science and Research (IJSR) \\ ISSN (Online): 2319-7064 \\ Index Copernicus Value (2013): 6.14 | Impact Factor (2014): 5.611}

multicystic ameloblastoma (SMA) 2. The unicystic ameloblastoma (UA) 3. The peripheral ameloblastoma (PA) 4. The desmoplastic ameloblastoma (DA), including the socalled hybrid lesions.

\section{Unicystic ameloblastoma}

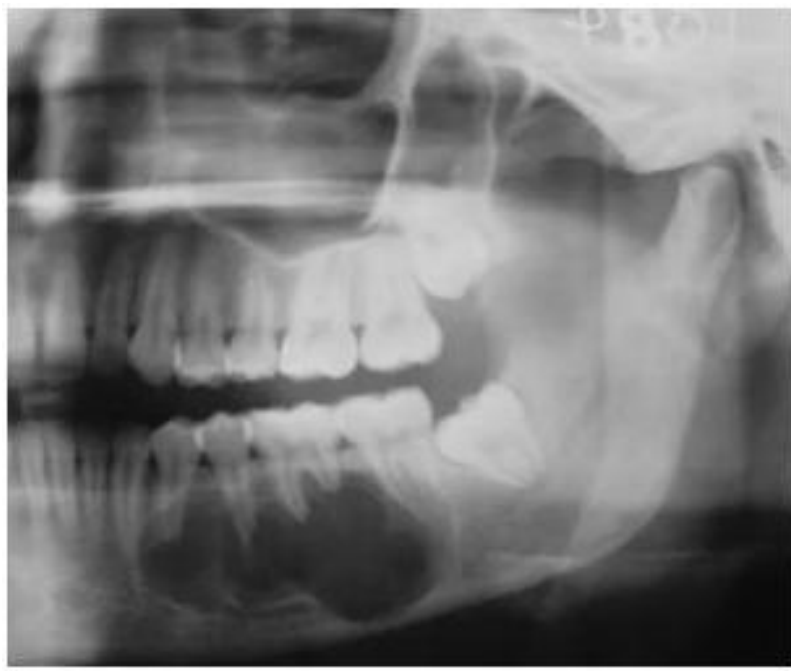

Unicystic type appears more frequently in a younger population ( $3^{\text {rd }}$ decade) than its solid counterpart ( $4^{\text {th }}$ decade).[7] In our case, the patient was 35-year-old. UAs were most commonly encountered in posterior mandible, followed by the parasymphysis region, anterior maxilla and the posterior maxilla.[7] The ratio of the maxilla: Mandible is 1:7 for the dentigerous variant, versus 1:4.7 for the nondentigerous type.[8] In our case also the lesion was nondentigerous type and was present on right body of the mandible extending up to the ramus region. Gender distribution shows a slight male predilection with a male: female ratio of 1.6:1. However, when the tumor is not associated with an unerupted tooth, the gender ratio is reversed to a male to female ratio of 1:1.8.[4] Most of the UAs are associated with an impacted tooth, the mandibular third molar being involved most often.[4] In our case, patient is a female, and the lesion is not associated with any unerupted/impacted teeth.

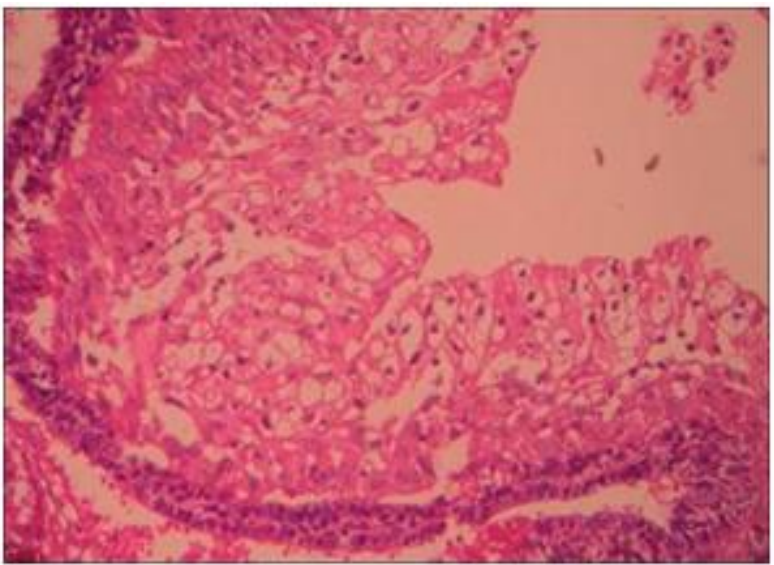

They are often asymptomatic until they are seen on a routine radiograph. As the lesion slowly enlarges, a slight, nontender swelling becomes apparent on clinical examination. This swelling is the result of an expansion of the cortical plates of the jaw and can be identified by palpation as hard and bony.[9] Our patient also showed a non-tender swelling with bicortical expansion.

Radiographically, UAs have been divided into two main patterns: Unilocular and multilocular. UAs have clear preponderance for the unilocular pattern.[4] The radiological features of UA are typically unilocular and there is a round area of radiolucency. Therefore this lesion is often misdiagnosed as an OKC/a DC.[프, $\underline{10]}$ It has been suggested that six radiographic patterns for UA can be identified ranging from well-defined unilocular to multilocular.[11] Eversole et al., identified predominant radiographical patterns for UA: Unilocular, scalloped, macromultilocular, pericoronal, interradicular, or periapical expansile radiolucencies.[8] where as our case showed atypical multilocular appearance with some straight septa within the lesion.

\section{References}

[1] White SC, Pharoah MJ. Oral radiology: Principles and interpretation, 5th edition, Missouri, Mosby, 2004, p384-409,410-57.

[2] White SC, Pharoah MJ. Oral radiology: Principles and interpretation, 5th edition, Missouri, Mosby, 2004, p410-57.

[3] Langlais RP, Langland OE, Nortjé CJ. Multilocular radiolucencies, chapter !3, Diagnostic Imaging of jaws. Williams and Wilkins, 1995,p327-84.

[4] Shaffer WG, Hine MK, Levy BM. A text book of Oral Pathology; 4th edition, W.B. Saunders company, Philadelphia, 1993, p258-317.

[5] Rajendran R, Sivapathasundharam B. Shafer's textbook of Oral Pathology, 5th edition, Elsevier, New Delhi, 2006, p381-91.

[6] Krammer IRH, Pindborg JJ, Shear M. WHO international Histological Classification of Tumors. Histological typing of Odontogenic Tumors, 2nd Edition Berlin-Heidelberg-New York: Springer Verlag: 1992 p11-4.

[7] Peter A Reichart, Hans P Philipsen. Odontogenic tumors and allied lesions by editorial and consensus conference held in Lyon, France (WHO,IARD) in july 2003 in conjunction with prepartion of new WHO Blue Book vol Pathology and genetics of tumors of head and neck, Quintessence publishing co ltd, United Kingdom, 2004, p21-23

[8] Robinson L, Martinez MG. Unicystic ameloblastoma. A prognostically distinct entity. Cancer 1977;40:2278-85.

[9] Peter A Reichart, Hans P Philipsen. Odontogenic tumors and allied lesions by editorial and consensus conference held in Lyon, France (WHO,IARD) in july 2003 in conjunction with prepartion of new WHO Blue Book vol Pathology and genetics of tumors of Rastogi S, Nijhawan S,et al; Radiolucent-Radiopaque Lesion In The Mandible- A Nobel Diagnostic Approach Journal of Clinical and Diagnostic Research. 2010 April ;(4):2300-2307 2307 head and neck, Quintessence publishing co ltd, United Kingdom, 2004, p77-86.

[10] Gardner DG. Plexiform unicystic ameloblastoma- a diagnostic problem in dentigerous cysts. Cancer 1981;47:1358-1363. 
[11] Li T-J, Wu Y-T, Yu S-F, Yu G-Y. Unicystic ameloblastoma- a clinicopathological study of 33 chinese patients. Am J Surg Pathol 2000;24:1385-92.

[12] Eversole LR, Leider AS, Strub D. Radiographic characteristics of cytogenic ameloblastoma. Oral Surg Oral med Oral Pathol 1984;57:572- 77.

[13] Reichart PA, Philipsen HP, Sonner S. Ameloblastoma: biological profile of 3677 cases. Eur J Cancer B Oncol 1995;31B:86-99.

[14] Ackerman GL, Altini M, Shear M. The Unicystic ameloblastoma- clinicopathologic study of 57 cases. J Oral Pathol 1988;17:541-46.

[15] Philipsen HP, Reichart PA. Unicystic ameloblastoma- a review of 193 cases from literature. Oral Oncol 1998;34:317-25.

[16] Neville BW, Damm DD, Allen CM, Bouqout JE. Odontogenic cysts and tumors, chapter 15, in Oral and maxillofacial pathology 2nd edition, W.B. Saunders company, 2002, p589-642.

[17]Leider AS, Eversole LR, Barkin ME. Cystic ameloblastoma. Oral Surg Oral med Oral Pathol 1985;60:624-630.

[18] Li TJ, Browne RM, Matthews JB. Expression of proliferating cell nuclear antigen (PCNA) and Ki-67 in unicystic ameloblastoma. Histopathology 1995;26:21928. [19] Li TJ, Browne RM, Matthews JB. Epithelial cell 